\title{
Analysis of Large-Signal and Small-Signal Instabilities in Piezoelectric Transformers Driving Cold Cathode Fluorescent Lamps
}

\author{
Giorgio Spiazzi, Simone Buso \\ Dept. of Information Engineering (DEI) - University of Padova (Italy) \\ Via Gradenigo 6/b, 35131 Padova - ITALY \\ Phone: +39-049-8277755 - Fax: +39-049-8277699 \\ E-mail: giorgio.spiazzi@dei.unipd.it, simone.buso@dei.unipd.it
}

\begin{abstract}
This paper investigates the behavior of voltage-fed piezoelectric transformers (PTs) driving cold cathode fluorescent lamps (CCFLs). It is shown that the non-linear equivalent lamp resistance can have a dramatic impact on the overall system performance, causing possible instabilities both at large and small signal level. The effects of the variable load resistance, with a negative small-signal value, are enhanced by the PT, that behaves like a high- $Q$ resonant circuit, and by the presence of the coupling inductor, usually placed between the half-bridge inverter and the PT to ensure zero-voltage commutation of the inverter switches. Such instabilities are investigated considering a constant frequency inverter where the lamp current is controlled by varying the dc-link voltage. SPICE simulations and analytical models are employed to explain the unstable behaviors observed in different experimental prototypes.
\end{abstract}

Keywords: piezoelectric transformers, cold cathode fluorescent lamps, lamp ballasts.

\section{INTRODUCTION}

Piezoelectric transformers (PTs) are rapidly replacing magnetic transformers in a lot of low-power applications. In particular, in the field of cold cathode fluorescent lamp (CCFL) inverters [1-5], they offer several advantages as compared to magnetic transformers, such as:

- $\quad$ inherent high gain at no load, that provides the lamp ignition voltage;
- load dependent gain that avoids the use of the ballast capacitor in series with the lamp;

- $\quad$ absence of leakage magnetic field;

- $\quad$ high Q factor, that gives low distorted sinusoidal lamp current waveform;

- $\quad$ small size and weight;

- high reliability due to the absence of a high voltage secondary winding.

Their behavior is well understood and the inverter design is easily carried out by using a PT linear model (Rosen-type, see $[6,7])$ and considering a constant load resistance corresponding to the lamp nominal power. However, the non linear nature of the lamp equivalent resistance can cause unexpected behaviors when used in conjunction with PTs. In the following sections, these behaviors are analyzed by using both an analytical approach and simulations, and are verified by experimental measurements.

\section{CONVERTER DESCRIPTION}

The converter structure we want to analyze is shown in Fig. 1: a half-bridge voltage-fed inverter supplies a symmetric square wave voltage $u_{i n v}$ to the PT through a coupling inductor $L_{s}$, that is employed to obtain zero-voltage commutations of the inverter switches. The well known Rosen-type model is used to describe the PT behavior around its fundamental resonant

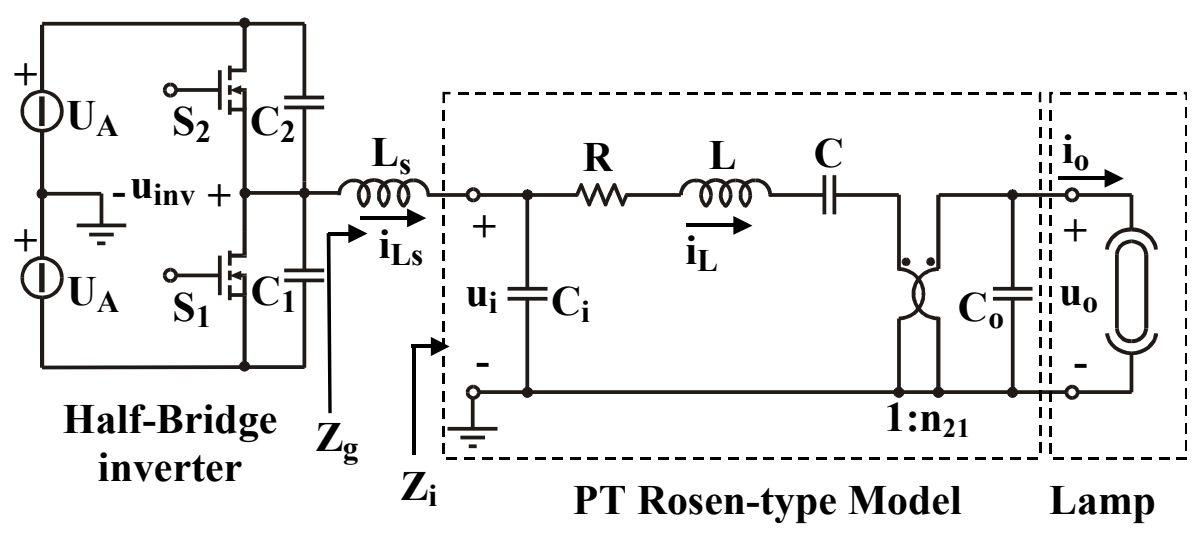

Figure 1. Scheme of the half-bridge inverter driving the PT for CCFLs 
mode. The Rosen-type model parameter values of the PT used in the experimental setup are reported in Table I. In the following, the theoretical analysis and all simulations will use these parameter values.

TABLE I. PIEZOELECTRIC TRANSFORMER FUJI T2508A: ROSEN TYPE MODEL PARAMETER VALUES

\begin{tabular}{|c|c|}
\hline $\mathrm{R}=5.37 \Omega$ & $\mathrm{C}=10.22 \mathrm{nF}$ \\
\hline $\mathrm{C}_{\mathrm{i}}=150.4 \mathrm{nF}$ & $\mathrm{C}_{\mathrm{o}}=15.48 \mathrm{pF}$ \\
\hline $\mathrm{L}=0.699 \mathrm{mH}$ & $\mathrm{n}_{21}=50.749$ \\
\hline
\end{tabular}

Even if many attempts have been made to avoid the coupling inductor by exploiting the PT internal inductive energy to discharge the input capacitance $C_{i}[1,8,9]$, we chose to use $L_{s}$ in order to be able to employ different PTs not specifically designed to achieve ZVS without the coupling inductor. Thus, as stated above, the coupling inductor $L_{s}$ is designed so as to make the input impedance $Z_{g}$ present a positive phase at the switching frequency or, in other words, to make the inverter output current lag the voltage. As an example, Fig. 2 reports the PT input impedance $\left(Z_{i}\right)$ phase and the overall input impedance $\left(Z_{g}\right)$ phase as a function of the normalized frequency $f_{N}=f / f_{S}$, where

$$
\mathrm{f}_{\mathrm{S}}=\frac{1}{2 \pi \sqrt{\mathrm{LC}}}=59.5 \mathrm{kHz}
$$

is the PT series resonance frequency. These curves have been derived using an $L_{s}$ value of $38 \mu \mathrm{H}$ and a load resistance of $152 \mathrm{k} \Omega$ corresponding to a lamp rated $910 \mathrm{~V}_{\mathrm{RMS}}$ at $6 \mathrm{~mA}_{\mathrm{RMS}}$. As we can see, between $\mathrm{f}_{1}=58.8 \mathrm{kHz}$ and $\mathrm{f}_{2}=64.3 \mathrm{kHz}$ the $Z_{g}$ input impedance phase is positive, thus giving a chance to have zero voltage turn-on for the inverter switches (the positive input impedance phase is only a necessary but not sufficient condition, because the inverter output current must be high enough at turn-on instants to charge and discharge the switch output capacitors). The presence of the coupling inductor modifies also the overall voltage conversion ratio. This can be observed in Fig. 3 that reports different voltage conversion ratios as a function of the normalized frequency $f_{N}: M_{P T}$ represents the PT intrinsic voltage gain, $M_{i}$ is the voltage gain between the RMS value of the inverter voltage fundamental component and the RMS value of the PT input voltage, and $M_{g}=M_{i} \cdot M_{P T}$ represents the overall voltage gain. It is interesting to note that the presence of the coupling inductor $L_{s}$ introduces an additional voltage gain $\left(M_{i}\right)$ that is frequency dependent and shows two resonance peaks: one below and the other above the PT resonance peak. These modifications make more problematic the control of the lamp current using the switching frequency as the control parameter, since, moving along the overall voltage conversion ratio curve, the gain (i.e. the curve slope) changes sign many times. This was one of the reasons that drove us toward the choice of the DC link voltage $U_{A}$ as the control parameter.

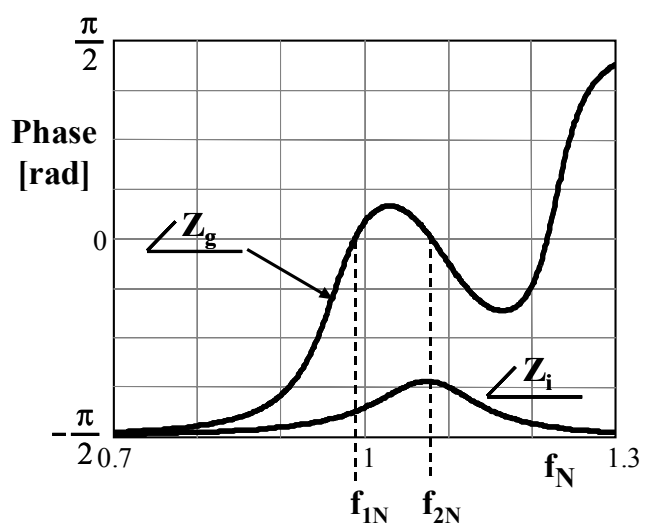

Figure 2. PT input impedance $\left(Z_{i}\right)$ phase and overall input impedance $\left(Z_{g}\right)$ phase as a function of normalized frequency $\mathrm{f}_{\mathrm{N}}=\mathrm{f} / \mathrm{f}_{\mathrm{S}}$

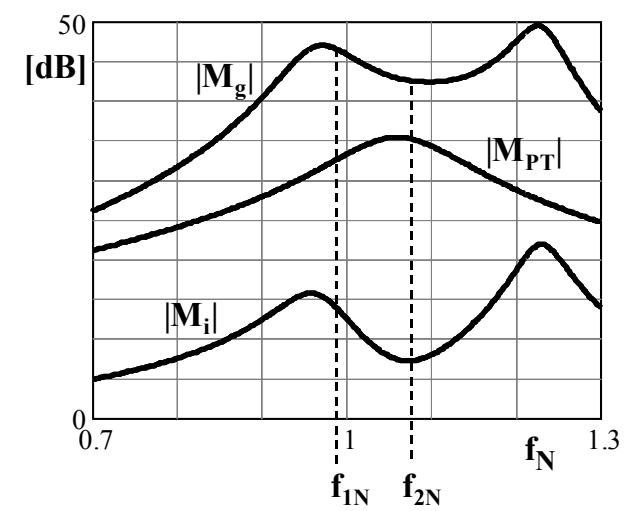

Figure 3. Voltage conversion ratios as a function of the normalized frequency $\mathrm{f}_{\mathrm{N}}$

We developed a prototype circuit and tested it on a $6 \mathrm{~W}$ CCFL $\left(910 \mathrm{~V}_{\mathrm{RMS}}\right.$ at $\left.6 \mathrm{~mA}_{\mathrm{RMS}}\right)$ and different types of commercial PTs, noting several unexpected phenomena. In open loop conditions, that is with no control of the lamp current, the system showed two different types of instability, one at the large signal level, apparently related to a non-linear relation between the $U_{A}$ voltage and the lamp current, and another at the small signal level. The former determined, in certain conditions, the impossibility to get smoothly to the desired operating point: the lamp drew a very small current even when a large input voltage was applied and then, all of a sudden, snapped to a very high current absorption. The latter determined persistent oscillations on every circuit variable around the desired operating point values. In the following we describe the investigation of these instability phenomena.

\section{LAMP MODEL}

Usually, analysis of piezoelectric lamp ballasts is carried out with a constant load resistance that simulates the lamp behavior at steady state and considering only the fundamental component $U_{l}$ of the inverter voltage $u_{i n v}$ (Fig. 1), thus simplifying the overall design process. Considering a constant load resistance allows to easily design the power supply in terms of dc input voltage, switching frequency, component stresses. Also the coupling inductance value can be easily determined, as explained in the previous section. However, neglecting the non linear nature of the lamp impedance hides 
many important phenomena, like those we are going to discuss in the following sections. To better describe the lamp behavior we considered two different lamp models, that were used both in simulations and for a mathematical analysis of the system. Both models are based on the approximation of the equivalent resistance variation according to the following equations:

Model A:

$$
\mathrm{R}_{\mathrm{L}}=\mathrm{a} \mathrm{e}^{-\mathrm{b} \mathrm{P}_{\mathrm{L}}},
$$

where the lamp resistance is approximated by an exponential function of the lamp power [10] and

$$
\text { Model B: } \mathrm{R}_{\mathrm{L}}=\frac{\mathrm{A}_{0}+\mathrm{A}_{1} \mathrm{e}^{-\mathrm{A}_{2} \mathrm{I}_{\mathrm{o}}}-\mathrm{A}_{3} \mathrm{e}^{-\mathrm{A}_{4} \mathrm{I}_{\mathrm{o}}}}{\mathrm{I}_{\mathrm{o}}},
$$

where the RMS lamp voltage is expressed as a combination of two exponential terms related to the RMS lamp current $I_{o}$, and the equivalent resistance is calculated accordingly [11].

All parameters have to be selected based on lamp measurements and are given in Table II.

TABLE II. ADOPTED LAMP MODEL PARAMETERS

\begin{tabular}{|l|l|}
\hline \multicolumn{1}{|c|}{ Model A parameters } & \multicolumn{1}{c|}{ Model B parameters } \\
\hline $\mathrm{a}=1.6 \mathrm{M} \Omega$ & $\mathrm{A}_{0}=610[\mathrm{~V}]$ \\
\hline $\mathrm{b}=0.43 \mathrm{~W}^{-1}$ & $\mathrm{~A}_{1}=1000[\mathrm{~V}]$ \\
\hline & $\mathrm{A}_{2}=200\left[\mathrm{~A}^{-1}\right]$ \\
\hline & $\mathrm{A}_{3}=1450[\mathrm{~V}]$ \\
\hline & $\mathrm{A}_{4}=1280\left[\mathrm{~A}^{-1}\right]$ \\
\hline
\end{tabular}

Actually, the model proposed in [10] also employs two exponential terms to better approximate the real lamp behavior, but we chose to use the simpler relation (2.a), since this was enough to reach a good match of the lamp characteristics. Fig. 4a shows the plots of relations (2.a) and (2.b), together with some measurements taken on our $6 \mathrm{~W}$ lamp. The lamp resistance models allow to derive the relation between the lamp voltage and current, that is reported in Fig. 4b: the characteristic shows the typical small-signal negative resistance at lamp currents higher than $2 \mathrm{~mA}_{\mathrm{RMS}}$.

\section{SMALL-SIGNAL ANALYSIS}

In principle, the interaction between the negative small-signal lamp resistance and the Rosen-Type PT model would always imply an unstable system. This fact can be easily explained, at least qualitatively: the negative lamp resistance makes any increase in the lamp voltage cause a decrease of the lamp current and a consequent increase of lamp resistance. With a bigger load resistance, the equivalent resonant circuit of the PT becomes less damped and, consequently, its voltage gain also increases, thus enhancing the initial lamp voltage change. This is a positive feedback system behavior. In practice, however, most of the combinations between PTs and CCFLs work quite well and no instability is observed. The reason for this is that relations (2.a) and (2.b) only hold at steady-state, while, in practice, when the lamp power changes the equivalent lamp resistance changes only after a certain delay. This is indirectly taken into account also in the lamp SPICE models, by using a first order low pass filter $[10,11]$ to
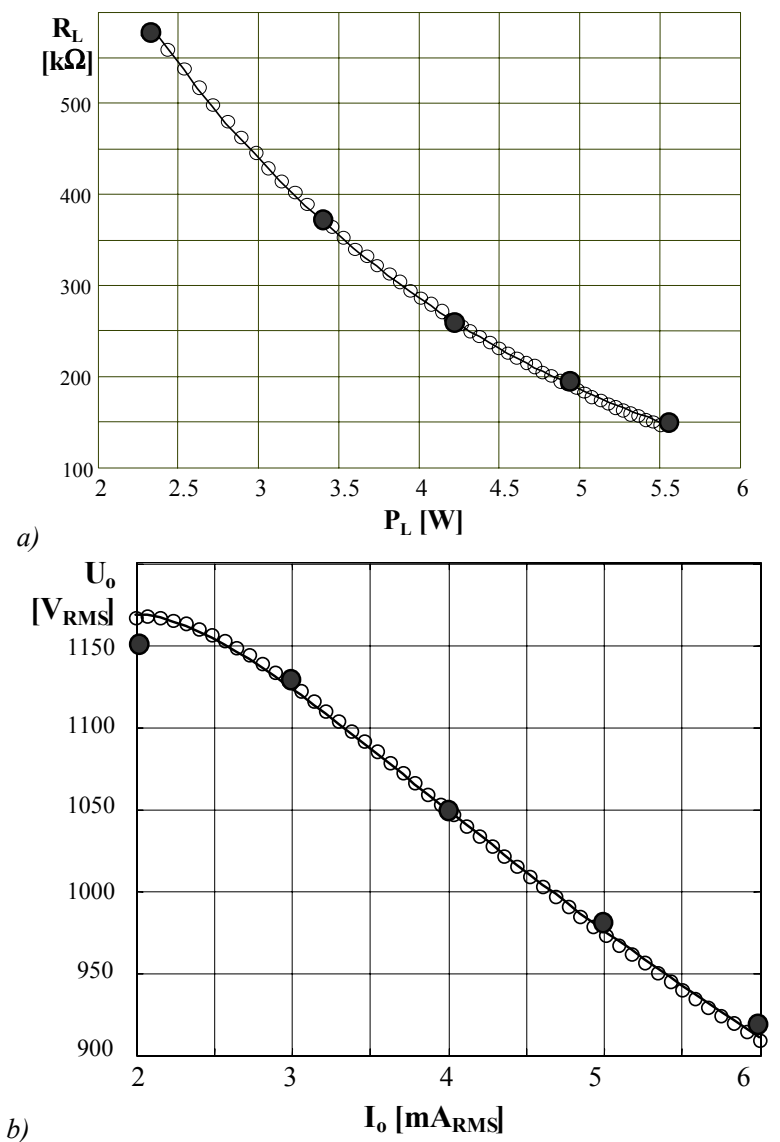

Figure 4. a) Lamp resistance as a function of lamp power according to: model A (solid line), model B (circles) and experimental measurements (dots); b) lamp voltage as a function of lamp current according to: model A (solid line), model B (circles) and experimental measurements (dots)

compute the average power and RMS current values required by equations (2.a) and (2.b) respectively. However, this delay is needed in the SPICE model to allow the generation of constant equivalent resistance values and, consequently, undistorted lamp current and voltage waveforms. In the physical device instead, the delay is inherent, being mainly related to the dependence of the lamp characteristics on temperature and to the non-zero thermal capacitance of the lamp. So, lamp SPICE models actually mix things up, under this point of view, since there is no relationship between the delay required by proper model operation and the physical delay implied by thermal phenomena inside the lamp. Since we are interested in the latter, we modified the lamp equivalent models by introducing a fast RMS current and average power computation, and a delay block just to describe the physical lamp behavior. This was done easily by using Simulink, while could be fairly complicated in SPICE. Once modified, the models were capable of reproducing the steady state behavior of the lamp and the internal lamp delay.

We now move to investigate the possible instability by linearizing each lamp model around an operating point under small-signal approximation. To this purpose, we begin perturbing (2.a) and obtaining: 


$$
\mathrm{U}_{\mathrm{o}}+\hat{\mathrm{u}}_{\mathrm{o}}=\left(\mathrm{I}_{\mathrm{o}}+\hat{\mathrm{i}}_{\mathrm{o}}\right) \mathrm{a} \mathrm{e}^{-\mathrm{b}\left[\left(\mathrm{U}_{\mathrm{o}}+\hat{\mathrm{u}}_{\mathrm{o}}\right)\left(\mathrm{I}_{\mathrm{o}}+\hat{\mathrm{i}}_{\mathrm{o}}\right)_{\mathrm{G}_{\mathrm{L}}}\right]}
$$

where $U_{o}$ and $I_{o}$ are steady state RMS lamp voltage and current, $\hat{u}_{o}$ and $\hat{\imath}_{o}$ are perturbed quantities, and $\mathrm{G}_{\mathrm{L}}(\mathrm{s})=1 /\left(1+\mathrm{s} / \omega_{\mathrm{L}}\right)$ is a low pass filter that takes into account the aforementioned delay. From (3), separating steady-state and small-signal perturbed terms, using the first order approximation for the exponential terms, and neglecting products of perturbed variables, we derived the following expression for the small-signal lamp impedance:

$$
\mathrm{Z}_{\mathrm{L}}=\frac{\hat{\mathrm{u}}_{\mathrm{o}}}{\hat{\mathrm{i}}_{\mathrm{o}}}=\mathrm{R}_{\mathrm{LN}}\left(\frac{\omega_{\mathrm{z}}}{\omega_{\mathrm{p}}}\right)\left(\frac{1+\frac{\mathrm{s}}{\omega_{\mathrm{z}}}}{1+\frac{\mathrm{s}}{\omega_{\mathrm{p}}}}\right),
$$

where $\mathrm{R}_{\mathrm{LN}}=\mathrm{a} \mathrm{e}^{-\mathrm{b} \mathrm{P}_{\mathrm{L}}}$ is the lamp resistance at the considered operating point $\left[\mathrm{U}_{0}, \mathrm{I}_{\mathrm{o}}\right], \mathrm{P}_{\mathrm{L}}=\mathrm{U}_{\mathrm{o}} \cdot \mathrm{I}_{\mathrm{o}}$ is the lamp power, and $\omega_{\mathrm{z}}=\omega_{\mathrm{L}}\left(1-\mathrm{b} \mathrm{P}_{\mathrm{L}}\right), \omega_{\mathrm{p}}=\omega_{\mathrm{L}}\left(1+\mathrm{b} \mathrm{P}_{\mathrm{L}}\right)$.

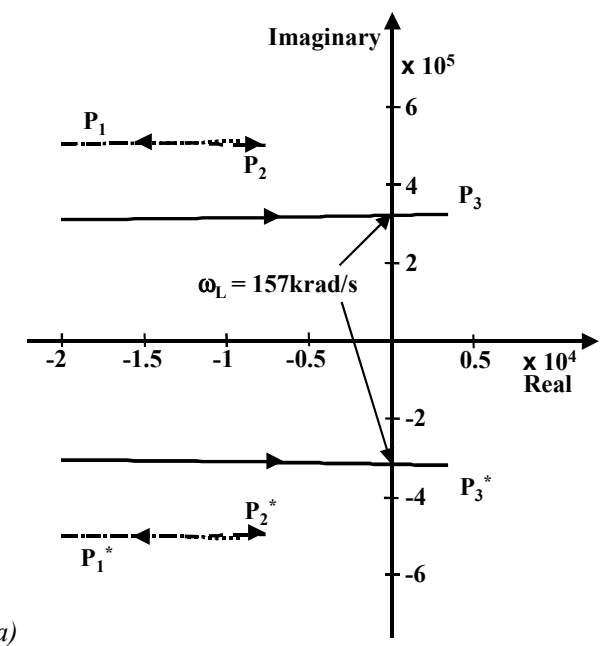

a)

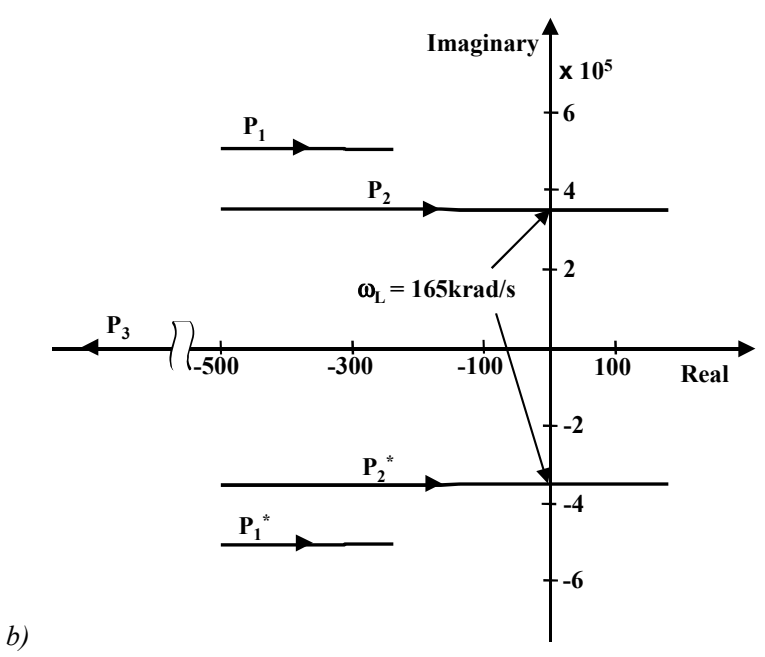

Figure 5. System pole locus for increasing values of lamp angular frequency $\omega_{\mathrm{L}}$ at $\mathrm{I}_{\mathrm{o}}=6 \mathrm{~mA}_{\mathrm{RMS}}$ and with $\mathrm{L}_{\mathrm{s}}=28 \mu \mathrm{H}$. a) model A, b) model B
The same procedure has been followed for model B, by perturbing (2.b) multiplied by the low-pass transfer function $G_{L}$ to account for the delay. This yields:

$$
Z_{L}=\frac{\hat{\mathrm{u}}_{\mathrm{o}}}{\hat{\mathrm{i}}_{\mathrm{o}}}=\frac{\mathrm{R}_{\mathrm{L} 0}}{1+\frac{\mathrm{s}}{\omega_{\mathrm{L}}}},
$$

where $R_{L 0}$ is given by:

$$
\mathrm{R}_{\mathrm{L} 0}=-\mathrm{A}_{1} \mathrm{~A}_{2} \mathrm{e}^{-\mathrm{A}_{2} \mathrm{I}_{\mathrm{o}}}+\mathrm{A}_{3} \mathrm{~A}_{4} \mathrm{e}^{-\mathrm{A}_{4} \mathrm{I}_{\mathrm{o}}} .
$$

Using (4) and (5) with the Rosen-Type PT model, we found the system poles, taking into account also the coupling inductor $L_{s}$. Fig. 5a reports the system pole trajectories for model A, Fig. $5 \mathrm{~b}$ for model B. Both are calculated at $\mathrm{I}_{\mathrm{o}}=6 \mathrm{~mA}_{\mathrm{RMS}}$, for increasing values of the lamp angular frequency $\omega_{\mathrm{L}}$ and with $\mathrm{L}_{\mathrm{s}}=28 \mu \mathrm{H}$. As we can see in Fig. 5.a at $\omega_{\mathrm{L}}=174 \mathrm{krad} / \mathrm{s}$ two complex conjugate poles cross the imaginary axis, giving rise to an unstable system. In Fig. 5.b we can see almost the same result. This means that the reasoning reported at the beginning of this section is theoretically sound, confirmed by two different lamp models. Above some critical $\omega_{L}$ (i.e. below a minimum internal lamp delay) the system may become unstable.

We verified that the occurrence of instabilities is a correct prediction both by simulations and by experimental tests. We simulated the system both with SPICE, using model A, and with Simulink, using both models $\mathrm{A}$ and $\mathrm{B}$, achieving the results shown in Fig. 6a: the simulated oscillation frequency is about $10 \mathrm{kHz}$ with model $\mathrm{A}$, but gets down to $7 \mathrm{kHz}$ with model B.

Finally, we checked that with our lamp, the instability occurs also in the experimental set-up. Measured instabilities are shown in Fig. 6b. The experimentally observed oscillation frequency is around $6 \mathrm{kHz}$, quite matching the expected value (at least with model B).

Several comments need to be done here. It is first of all important to notice that our system operates in an open loop arrangement: there is no feedback loop wrapped around it. So we are discussing inherent instability phenomena, not related to bad compensator design. Observing the waveforms of Fig. 6 we can see that the oscillation frequency for the system is not equal to the frequency of the system poles at the critical $\omega_{\mathrm{L}}$ value (which is easily computable from Fig. 5, given the imaginary part magnitude of the poles at the crossover). This is because we are observing a highly non-linear system, where the resulting oscillation frequency is a limit-cycle frequency. This is started and sustained by the small signal instability, but it is not easily related to the latter.

Given the relatively high value of $\omega_{L}$, the simulation with SPICE is not always capable of replicating the phenomena described in Fig. 6, because the lamp waveforms tend to be too distorted. For lower $\omega_{L}$ values, that are possible in different conditions, SPICE and Simulink models predict similar behaviors.

Finally, it is worth noting that we found similar behaviors also with two other types of PT's always showing an 


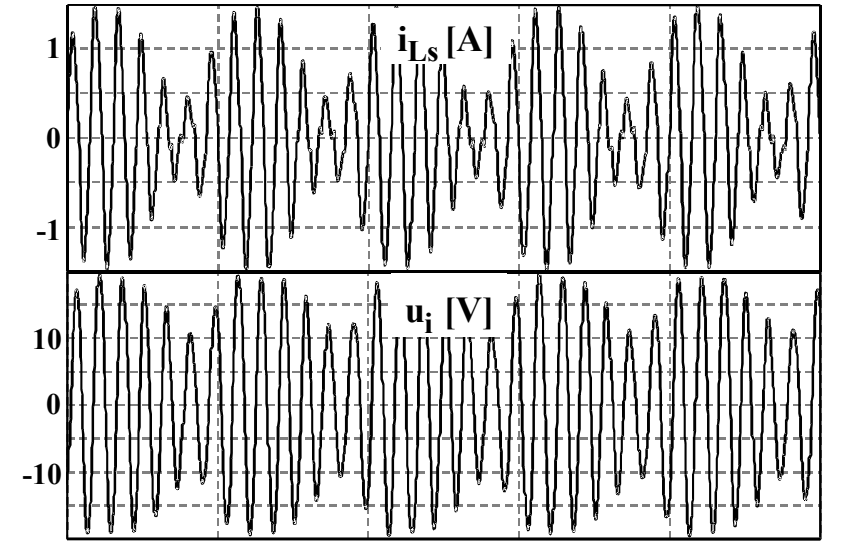

a)

\section{Time[100 $\mu$ s/div]}

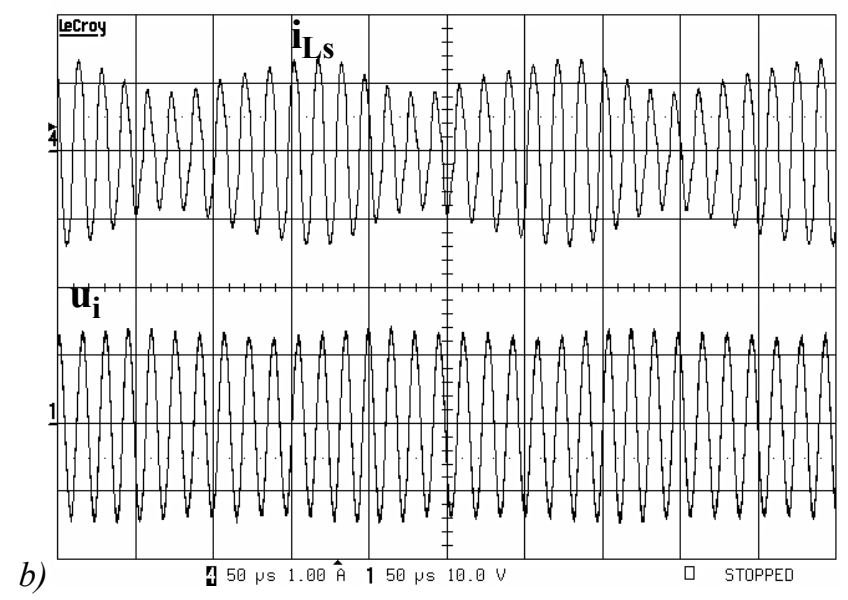

Figure 6. Small-signal instability observed with $\mathrm{L}_{\mathrm{s}}=28 \mu \mathrm{H}$ at $\mathrm{f}_{\mathrm{s}}=$ $65 \mathrm{kHz}$ and $\mathrm{U}_{\mathrm{A}}=7.33 \mathrm{~V}$

Upper curve: inverter output current $\mathrm{i}_{\mathrm{L} s}$; lower curve: PT input voltage $\mathrm{u}_{\mathrm{i}}$ a) simulated waveforms with $\omega_{\mathrm{L}}=150 \mathrm{krad} / \mathrm{s}$ (model A); b) experimental measurements: $i_{L s}[1 \mathrm{~A} /$ div $], u_{i}[10 \mathrm{~V} /$ div $]$

oscillation frequency between $5 \mathrm{kHz}$ and $6 \mathrm{kHz}$, that are not reported here for conciseness.

\section{LARGE-SIGNAL ANALYSIS}

The second aspect we are going to investigate is the steady-state gain relation between the controlled variable, i.e. the lamp RMS current $I_{o}$, and the input variable, i.e. the half-bridge de voltage $U_{A}$. To this purpose a simple MATLAB program was used that, starting from the lamp current, calculates the lamp voltage and resistance from both models $\mathrm{A}$ and B, and, from the Rosen-type model parameter knowledge, finds the dc voltage value that produces the desired lamp voltage, at a given switching frequency. Fig. 7 shows the results of the analysis done at $f_{s}=65 \mathrm{kHz}$ for two different values of the coupling inductor $\mathrm{L}_{\mathrm{s}}$, together with experimental measurements: as we can see, for $\mathrm{L}_{\mathrm{s}}=54.9 \mu \mathrm{H}$, the gain curve is no longer monotonic. This means that at a given input dc voltage may correspond three different lamp current values, one of them being an unstable operating point.

In spite of significant quantitative differences, the qualitative behavior is well predicted by the model that

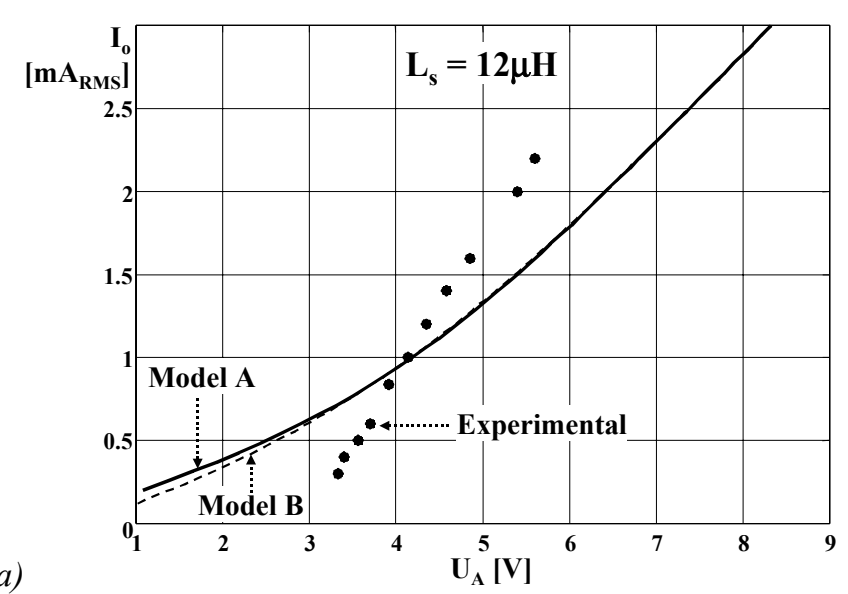

a)

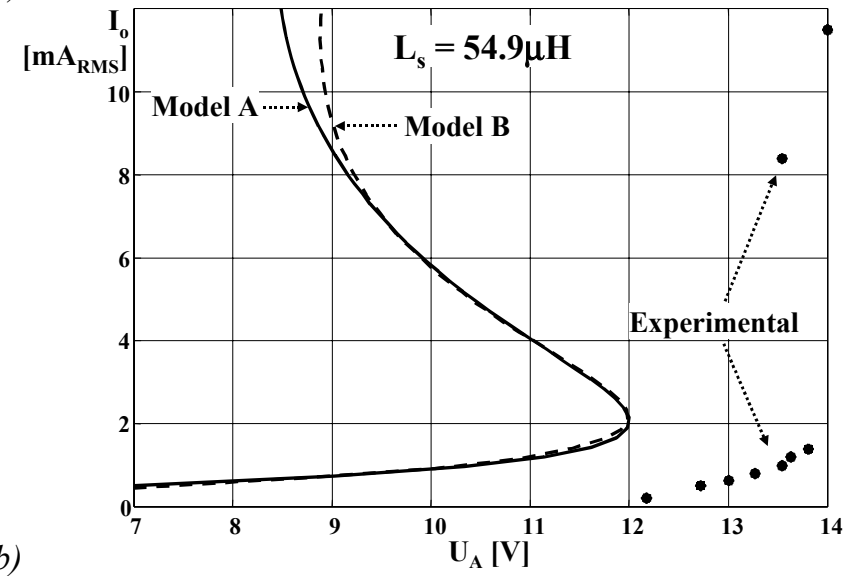

Figure 7. Comparison between predicted and measured gain curves for two different coupling inductor values: a) $\mathrm{L}_{\mathrm{s}}=12 \mu \mathrm{H}$, b) $\mathrm{L}_{\mathrm{s}}=54.9 \mu \mathrm{H}$ $\left(f_{\mathrm{s}}=65 \mathrm{kHz}\right)$

correctly explains the observed phenomena. Plotting these curves for different $L_{s}$ values can be very helpful in the selection of the coupling inductor, allowing to avoid the uncontrollability of the system. Fig. 8 shows the dependence of the input $\mathrm{DC}$ voltage $\left(\mathrm{U}_{\mathrm{A}}\right)$ to $\mathrm{RMS}$ lamp current gain relation on the $L_{s}$ value. It is possible to see that increasing $L_{s}$

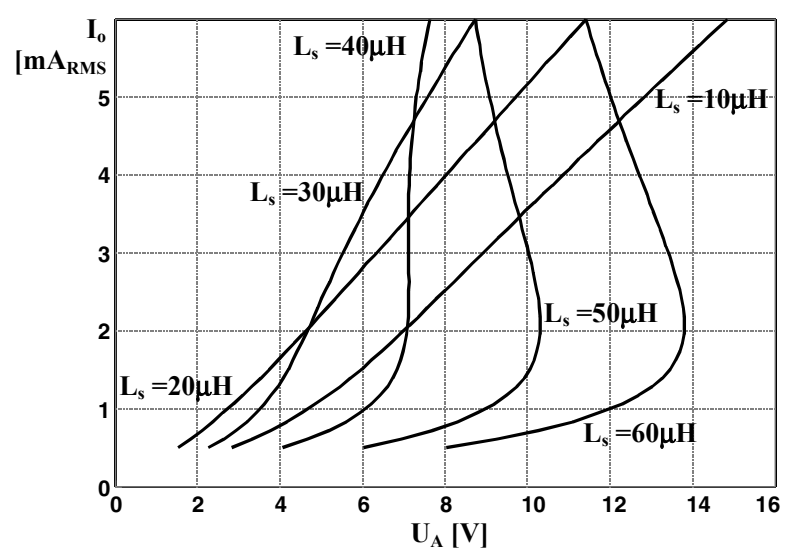

Figure 8. Input DC voltage to RMS lamp current gain curves for different coupling inductor values $\left(\mathrm{f}_{\mathrm{s}}=65 \mathrm{kHz}\right)$. Curves plotted using Model A 
above $30 \mu \mathrm{H}$ determines a severe non linearity of the characteristic that makes the system uncontrollable. These curves, together with the ones related to soft-switching converter operation, reported in Section II, allow to choose an initial $\mathrm{L}_{\mathrm{s}}$ value. This needs to be experimentally refined, since the model predictions are not sufficiently reliable (Fig. 7) for direct design. The critical $\mathrm{L}_{\mathrm{s}}$ value may be significantly different from the expected one.

Finally, it is worth noting that the large signal instability discussed here is closely related to the chosen control strategy (control of lamp current by dc link voltage variation). Different strategies, like the variable frequency approach could behave differently. Further investigation is required to clarify this point.

\section{CONCLUSIONS}

It has been shown that the non-linear equivalent lamp resistance of a cold cathode fluorescent lamp can cause instabilities when the lamp is driven by a piezoelectric transformer. Such instabilities depend not only on the PT parameters and lamp characteristics, but also on the coupling inductor usually employed between the inverter and the PT in order to achieve soft commutation of the inverter switches. SPICE simulations and analytical models have been employed to justify the unstable behaviors observed in different experimental prototypes.

\section{REFERENCES:}

[1] Ray L. Lin, Fred C. Lee, Eric M. Baker and Dan Y. Chen, "Inductor-less Piezoelectric Transformer Electronic Ballast for Linear Fluorescent Lamp" IEEE Applied Power Electronic Conference Proc (APEC), 2001, pp.664-669.
[2] Chin S. Moo, Wei M. Chen, Hsien K. Hsieh, "An Electronic Ballast with Piezoelectric transformer for Cold Cathode Fluorescent Lamps" Proceedings of IEEE International Symposium on Industrial Electronics (ISIE), 2001, pp. 36-41.

[3] H. Kakehashi, T. Hidaka, T. Ninomiya, M. Shoyama, H. Ogasawara, Y. Ohta, "Electronic Ballast using Piezoelectric transformer for Fluorescent Lamps" "IEEE Power Electronics Specialists Conference Proc. (PESC), 1998, pp.29-35.

[4] Jim-Hong Chung, Seung-Min Lee, Mike Myung-Ok Lee and Yang Ho Moon, "High power $30 \mathrm{~W}$ and high efficiency $80 \%$ piezoelectric transformer for Electronic Ballast”, ASIC'99, Proceedings pp.131-134.

[5] Sung-Jim, Kyu-Chan Lee and Bo H. Cho, "Design of Fluorescent Lamp Ballast with PFC using Power Piezoelectric Transformer" IEEE Applied Power Electronic Conference Proc. (APEC), 1998, pp.1135-1141.

[6] Ehson M. Syed, Francis P. Dawson, Edward S. Rogers "Analysis and Modeling of Rosen Type Piezoelectric Transformer" IEEE Power Electronics Specialists Conference PESC'01, Proceedings pp. 17611766, 2001.

[7] Ray L. Lin, Eric Baker and Fred C. Lee, "Characterization of Piezoelectric Transformers", Proceedings of Power Electronics Seminars at Virginia Tech, Sept. 19-21, 1999, pp. 219-225.

[8] Svetlana Bronstein and Sam Ben-Yaakov, "Design considerations for Achieving ZVS in a Half Bridge Inverter that Drives a Piezoelectric Transformer with No Series Inductor" IEEE Power Electronics Specialists Conference PESC'02.

[9] M. Sanz, P. Alou, R. Prieto, J. A. Cobos and J. Uceda, "Comparison of different alternatives to drive Piezoelectric Transformers" IEEE Power Electronics Specialists Conference, PESC'02, Proceedings pp.358-364, 2002.

[10] M. Cervi, A. R. Seidel, F. E. Bisogno, R. N. do Prado, "Fluorescent Lamp Model Based on the Equivalent Resistance Variation," IEEE Industry of Application Society (IAS) CDROM, 2002.

[11] Onishi N., Shiomi T., Okude A., Yamauchi T., "A Fluorescent Lamp Model for High Frequency Wide Range Dimming Electronic Ballast Simulation" IEEE Applied Power Electronic Conference Proc. (APEC), 1999, pp.1001-1005. 